$p$-ISSN 1693-9484, $e$-ISSN : 2621-8313

Majalah Ilmiah Bahari Jogja (MIBJ)

Vol. 18 No. 1, Februari 2020 (116-126)

DOI : $10.33489 /$ mibj.v18i1.232

(C) 2020 Sekolah Tinggi Maritim Yogyakarta

\title{
Peran Crude Oil Washing System (COW) Pada Kapal Tanker
}

\author{
Prasetya Sigit Santosa ${ }^{1^{*}}$ \\ ${ }^{1}$ Prodi Permesinan Kapal, Sekolah Tinggi Maritim Yogyakarta, Jl.Magelang Km 4,4, \\ Yogyakarta 55284, Indonesia \\ *Corresponding Author. E-mail : sigitamy65@gmail.com. Telp: 0818270011
}

\begin{abstract}
Abstrak
Crude Oil Washing System adalah sistim yang menggunakan Crude Oil atau minyak mentah sebagai medium pencuci. Tanki-tanki muatan diusahakan bersih dari sisa-sisa muatan minyak mentah sehingga balas bersih dapat dimuat dalam tanki yang sudah dibilas tadi dengan hanya mengadakan sedikit pembilasan lebih dahulu dengan air sehingga akibat pollusi akan sangat terbatas. Pipa yang digunakan yang dihubungkan dengan pipa muatan harus dibuat dari pipa baja atau sejenisnya yang kekuatannya cukup untuk menahan tekanan minyak yang diperlukan, dan juga harus terpasang (fixed) dan diperkuat dengan baik. Crude Oil Washing System harus dipasang permanent dan terpisah sama sekali dari system pipa-pipa yang lain kecuali yang disambung kepipa muatan. Juga pipa-pipa tersebut harus dilengkapi dengan relief system guna mengontrol tekanan dalam pipa jangan sampai berlebih, relief pipe system ini harus dihubungkan kembali dengan bagian isap dari Supply Pump. Sedangkan keuntungan menggunakan Crude Oil adalah sudah tersedia dikapal dengan cara resirkulasi, efektif untuk menghilangkan sediment dan sisa-sisa minyak yang melekat dalam tanki (good Carrier) dan dibongkar bersama-sama dengan muatan, tidak menimbulkan karat serta tidak ada kemungkinan emulsi air dan minyak jadi mengurangi bahaya pollusi. Semua pekerjaan Crude Oil Washing harus sudah selesai sebelum kapal meninggalkan pelabuhan bongkar muatan terakhir.Jika sampai dilaksanakan Crude Oil Washing antara dua pelabuhan bongkar pada tanki-tanki tersebut harus tetap kosong untuk pemeriksaan pada pelabuhan-pelabuhan berikutnya sebelum diisi dengan air balas.
\end{abstract}

Kata Kunci : Pembilasan tanki, minyak mentah

\section{Abstract}

Crude Oil Washing System is a system that uses Crude Oil or crude oil as a washing medium. The cargo tanks are kept clean from the remnants of the crude oil load so that clean replacements can be loaded in the previously rinsed Tank by only making a little rinse first with water so that the effects of Pollution will be very limited. The pipes used which are connected to the loading pipes must be made of steel pipes or the like which have sufficient strength to withstand the required oil pressure, and must also be fixed (fixed) and strengthened properly. The Crude Oil Washing System must be installed permanently and completely separated from the other pipe systems except those connected to the pipe. Also the pipes must be equipped with a relief system to control the pressure in the pipe not to be excessive, the relief pipe system must be connected back to the suction part 
of the Supply Pump. While the benefits of using Crude Oil are already available on the ship by recirculation, effective for removing sediment and the remnants of oil attached to the tank (good carrier) and disassembled together with the load, do not cause rust and there is no possibility of water and oil emulsions to reduce the danger of pollution. All Crude Oil Washing work must be completed before the ship leaves the final unloading port. If until Crude Oil Washing is carried out between the two unloading ports in the tanks, it must remain empty for inspection at the following ports before being filled with ballast water.

Keywords : Flushing the tank, crude oil

\section{PENDAHULUAN}

Crude Oil Washing System adalah sistim yang menggunakan Crude Oil atau minyak mentah sebagai medium pencuci.Tanki muatan yang sudah "Inerted" dibilas atau dicuci dengan Crude Oil tersebut sedang dibongkar dengan cara memisahkan sebagian kecil dari Crude Oil tersebut melalui Mesin Tank Cleaning yang dipasang tetap atau fixed dari atas Deck kedalam setiap Tanki muatan dalam jumlah yang cukup sehingga memungkinkan semua Crude Oil dan Tanki dapat dibongkar.

Tanki-tanki muatan diusahakan bersih dari sisa-sisa muatan minyak mentah sehingga balas bersih dapat dimuat dalam Tanki yang sudah dibilas tadi dengan hanya mengadakan sedikit pembilasan lebih dahulu dengan air sehingga akibat Pollusi akan sangat terbatas. Dengan cara demikian bahaya pembuatan Sludge atau sisa-sisa minyak dari Tanki Balas kotor atau dari pembersihan Tanki muatan dapat dihindari.

Kita mulai dengan perbandingan waktu pelaksanaan pembersihan tanki muatan (cleaning tank) untuk docking repair. Untuk itu diambil contoh dari kapal-kapal BP. Tanker London sesuai penyelidikan mereka selama ini.

Kapal yang tanpa menggunakan COW sebelumnya maka pembersihan (Tank Cleaning) VLCC ukuran 250.000 DWT memakan waktu sampai 14 hari, sedangkan Kapal Tanker yang sama dengan menggunakan Crude Oil Washing System selama operasi maka hanya memerlukan waktu 2 hari untuk membilas (quick Wash) COT sampai siap untuk Docking Repair Ready for hot Work.

Disamping itu dibandingkan dengan menggunakan air sebagai medium pencuci dapat menimbulkan problem pollusi dimana terjadi emulsi air dan minyak, menimbulkan karat dalam tanki karena penggunaan air laut, karena banyak air dalam slop tank dan emulsi maka akan terjadi dead frieg atau pengurangan daya muat dari kapal, kurang efektif untuk membilas minyak karena kurang efektif sebagai solvent kecuali kalau dicampur dengan Chemical, dan lebih banyak air laut masuk ke refinery bersama Crude Oil Stream waktu bongkar muatan. 


\section{KAJIAN LITERATUR}

\section{Kriteria dan design special crude oil whasing system}

Kriterianya tergantung pada kebutuhan yang diperlukan untuk pengoperasiannya dan kontrol dari pelaksanaan peraturan dan procedur COW pada tangki muatan Crude Oil, baik yang berlaku untuk : Existing Crude Oil Carrier (Tanker yang memuat minyak mentah) 40.000 DWT keatas sesuai peraturan TSPP 1978 dan Marpol 1973 mengenai pencegahan Polusi, maupun untuk kapal crude oil carrier yang baru ukuran 20.000 DWT keatas sesuai peraturan Marpol Protocol 1973.

Jenis Crude Oil yang akan diangkut, tidak dapat digunakan sebagai medium pencuci (COW), padahal kapal tersebut hanya dilengkapi dengan peralatan Crude Oil Washing System, maka kapal yang akan digunakan harus kapal yang mempunyai "Segregated Ballast Tank" atau dengan "Dedicated Clean Ballast Tank" sesuai ketentuan peraturan 13 (7) dan 13 (9) Annex 1 Marpol 1973.

Arrival Ballast yang berarti air ballast bersih (clean Ballast) sesuai Reg. 1 (16) pada Annex 1 Marpol Protocol 1973. Dimana kalau air balas yang dianggap bersih dibuang pada pelabuhan muat pada keadaan air tenang tidak akan terlihat lagi tanda-tanda adanya minyak yang mengapung dan sludge Emulsi dibawah permukaan air atau pantai yang berhubungan dengan daerah pelabuhan muat tersebut.

Jadi jika air balas bersih melalui "Oil monitoring System" maka jumlah minyak dalam air balas tersebut tidak boleh lebih dari 15 ppm. (part permillion), sedangkan Departure Ballast adalah air ballast selain dari Arrival Ballast.

\section{Special design dari cow}

1. Piping system (sistim pipa)

Pipa yang digunakan yang dihubungkan dengan pipa muatan harus dibuat dari pipa baja atau sejenisnya yang kekuatannya cukup untuk menahan tekanan minyak yang diperlukan, dan juga harus terpasang (fixed) dan diperkuat dengan baik.

Crude Oil Washing System harus dipasang permanen dan terpisah sama sekali dari system pipa-pipa yang lain kecuali yang disambung kepipa muatan. Juga pipa-pipa tersebut harus dilengkapi dengan relief system guna mengontrol tekanan dalam pipa jangan sampai berlebih, relief pipe system ini harus dihubungkan kembali dengan bagian isap dari Supply Pump.

Selanjutnya tidak boleh ada bagian dari COW System ini yang terpasang didaerah Kamar Mesin. Kalau pembersih tanki dilengkapi dengan air, maka Heater-heater tersebut harus betul diisolasi dengan double Valves atau ditutup dengan plat (di Blank) terhadap COW system selama berlangsung Crude Oil Washing.

Kalau pipa-pipa untuk COW, juga digunakan untuk air sebagai pembilas tanki, pipa-pipa tersebut harus dibuat sedemikian rupa sehingga kalau akan digunakan untuk pembilasan dengan air, maka minyak harus dapat dikeringkan lebih dulu (drain) dari dalam pipa-pipa tersebut ke tempat-tempat yang sudah ditentukan seperti kedalam Tanki muatan atau Slop tank. 
Diameter dari system pipanya harus ditentukan sedemikian rupa sehingga semua Tank Cleaning Machine yang diperlukan sesuai petunjuk dalam "Operation and Manual" dapat dioperasikan secara serentak pada tekanan dan kapasitas yang sama terutama untuk satu ruangan muatan, Tank Cleaning Machine tersebut harus dapat beroperasi bersamaan dengan tekanan 1,5 kali dari tekanan kerja.

Pipa-pipa supply untuk COW ini harus betul-betul terpasang kuat pada struktur dari kapal pada tempat-tempat yang sesuai dan juga dilengkapi dengan peralatan-peralatan seperti expansion joint untuk menampung pemuatanpemuatan dari pipa dan pergerakan-pergerakan lainnya dari kapal. Penguatpenguat untuk COW system harus betul-betul dipasang sedemikian rupa sehingga menggambarkan pemakaian dari pada peralatan-peralatan ini.

2. Mesin Pembilas Tanki atau Tank Washing Machines

Mesin-mesin yang digunakan untuk COW ini harus terpasang tetap dan rencana pemasangannya harus dengan persetujuan dari Badan Pemerintah. Mesin-mesin ini akan dipasang disetiap tanki muatan, dan cara pemasangan serta metode-metode penguat yang digunakan harus sesuai persetujuan dan petunjuk dari badan Pemerintah tersebut.

Setiap mesin Tanki Cleaning ini harus dapat diisolasi dengan "Stop Valve" dari pipa suppy (Supply line). Kalau mesin perlu dipindahkan atau dibuka maka harus disiapkan alat-alat untuk menutup (blank) pipa supplay tersebut ke Mesin selama Mesin tersebut dipindahkan.

Juga untuk lobang tanki tempat Mesin tersebut terpasang harus ditutup dengan plat atau alat penutup yang sama.

Jumlah Mesin dan tempat-tempat pemasangannya harus sesuai persetujuan dan petunjuk dari badan Pemerintah dan harus diusahakan agar jumlah dan lokasinya sedemikian rupa pada setiap COT sehingga semua bagian-bagian vertical dan horizontal dari kontruksi tanki dapat dibilas dengan baik. Pembilasan ini dilaksanakan dengan ketentuan-ketentuan sebagai berikut:

a. Untuk bagian konstruksi horizontal, alas tanki, bagian atas tanki stringers dan konstruksi yang lebih besar dalam tanki tidak boleh lebih dari $10 \%$ bagianbagian tersebut yang tidak dapat disemprot langsung dengan Crude Oil Washing atau dibilas dengan minyak mentah.

b. Untuk bagian vertical dari dinding-dinding tanki, tidak boleh lebih dari $15 \%$ bagian yang tidak dapat disemprot langsung, bagian-bagian tersebut seperti Deck dan Bottom tranversr, main ginders, stringer-stringer vertical dan bagian-bagian lain yang menunjang konstruksi vertical.

c. Untuk existing Crude Tanker atau Tanker yang sudah dibangun sebelum peraturan ini berlaku yang konstruksi tanki-tankinya mungkin ada yang sangat complex maka badan Pemerintah memperbolehkan melebihi ketentuan (a) dan (b) diatas dengan ketentuan bahwa tidak boleh melebihi $10 \%$ untuk bagian Horizontal dan $15 \%$ untuk bagian vertical dari total keseluruhan luas dari Tanki-tanki muatan.

Karena itu kemungkinan pada penempatan Mesin-mesin Tank Cleaning ada beberapa tempat dipasang mesin-mesin yang tidak sama type dan kapasitasnya tergantung dari konstruksi dari tanki-tanki yang bersangkutan. 
Sebab itu untuk konstruksi Tanki dari Tanker-tanker baru yang harus dilengkapi dengan COW system harus betul-betul diperhatikan dan diperhitungkan mengenai penempatan Mesin Tank Cleaning agar sesuai ketentuan (a) dan (b) diatas dengan jalan mengatur konstruksi dalam tanki-tanki muatan tersebut dan rencana peletakan dari Mesin-mesin itu nantinya.

\section{HASIL DAN PEMBAHASAN}

\section{Pemeriksaan dan Verifikasi}

Tanki harus diketahui secara jelas mengenai bersih tidaknya tanki-tanki dari minyak dan untuk verifikasi dari design peletakan mesin-mesin Tank Cleaning baik jumlah maupun tempatnya, maka perlu diadakan pemeriksaan dalam Tanki-tanki setelah selesai melaksanakan Crude Oil Washing.

Tetapi sebelum masuk, Tanki-tanki tersebut harus dibilas dengan air lebih dulu sesuaii ketentuan-ketentuan dalam "Operation and Equipment Mannual". Bagian dasar tanki mungkin dibilas dengan air kemudian air tersebut diisap keluar untuk mengeluarkan sisa-sisa minyak yang masih melekat sebelum diadakan "Gas Free" untuk bisa dimasuki oleh petugas pemeriksa.

1. Pemeriksaan ini dilakukan untuk menentukan bahwa tangki betul-betul sudah

2. bebas dari endapan-endapan dan minyak-minyak yang melekat.

3. Untuk verifikasi pekerjaan Stripping yang efektif dan system pengeringan, pengukuran harus dilakukan pada jumlah minyak yang mengapung diatas air pada "Departure Ballast". Perbandingan volume minyak tersebut terhadap volume total dari air "Departure Ballast" tidak boleh lebih dari 0,00085.

Test ini dilakukan pada tanki-tanki yang sudah selesai melaksanakan COW dan pekerjaan Stripping seperti pada persiapan pemeriksaan Tanki-tanki diatas, yang tidak memerlukan pembilasan air lebih dulu atau air flushing seperti pada diatas.

4. Untuk verifikasi disain, instalasi dan cara operasi dari system, "Arrival Ballast", dimana tanki yang digunakan untuk ballast tersebut sebelumnya diadakan Crude Oil Washing, pembilasan dan pembersihan dengan air.

Sesuai program yang telah ditentukan dalam "Operation and Equipment Manual", dan dibuang seluruhnya pada pelabuhan Loading Port, melalui system "Oil Monitoring" yang telah disetujui oleh pemerintah, dimana minyak yang bercampur dengan air balas tersebut tidak lebihd ari $15 \mathrm{ppm}$.

Pemeriksaan dan verifikasi semacam ini untuk kapal-kapal yang sama dalam hal-hal tertentu seperti bentuk konstruksi tanki dan penempatanpenempatan peralatan Tank Cleaning Machine dengan kapasitas yang sama, cukup dilakukan pada salah satu kapal saja dan kalau sudah memenuhi maka hasil pemeriksaan berlaku untuk semua kapal-kapal yang sama.

Jenis Tank Cleaning Machine yang bisa digunakan ada beberapa macam :

Mesin Tank Cleaning yang dipasang diatas Deck Nozzle masuk dalam tanki dilengkapi dengan "Program System" untuk mengatur pergerakan nozzle, sudut elevasinya, putaran dan naik turunnya nozzle sesuai kebutuhan.

Mesin Tank Cleaning seperti (a) diatas tapi tidak dilengkapi "Program System" dimana sesuai ketentuan harus dilengkapi dengan metode lain untuk 
dapat mengontrol pelaksanaan Crude Oil Washing tersebut sesuai persetujuan dari badan Pemerintah.

Submerge Machine berarti bahwa tidak mempunyai "Program System" jadi agar bisa memenuhi persyaratan terutama mengenai ketentuan-ketentuan pembilasan tanki diatas, maka harus putaran-putaran dan kerja dari nozzle harus dapat memungkinkan untuk verifikasi dengan jalan : indicator yang terpasang diluar tanki, mendeteksi sifat karakteristik bunyi dari mesin pada setiap phase dari cycle, dengan mengadakan gas free tanki tersebut dan memeriksa langsung cara kerja dari mesin-mesin yang ada didalamnya dengan menggunakan air untuk mencek seperti ini paling kurang satu kali dalam waktu 12 bulan. Dan setiap hasil verifikasi harus dicatat dalam "Oil Record Book".

Metode-metode untuk verifikasi ini disebutkan dalam buku "Operation and Equipment Mannual" dari peralatan-peralatan COW System.

\section{Pompa (Pumps)}

Pompa yang digunakan guna mensupplay minyak ke Mesin Tank Cleaning bisa langsung menggunakan cargo Pump atau Pompa yang disediakan khusus untuk itu.

Kapasitas dari pompa yang digunakan harus cukup untuk menyuplai jumlah dan tekanan minyak yang dibutuhkan pada jumlah Mesin Tank Cleaning yang dibutuhkan untuk beroperasi dalam waktu bersamaan sesuai Buku petunjuk "Operation and Equipment Mannual”.

Kapasitas dari pompa-pompa yang dimaksud diatas harus sedemikian rupa sehingga kebutuhan seperti yang disebutkan pada (a) diatas dapat dipenuhi pada setiap pompa yang digunakan.

Perencanaan pompa dan pipa-pipa diatur sedemikian rupa sehingga pelaksanaan Crude Oil Washing bisa berjalan semestinya dan efektif walaupun salah satu dari pompa-pompa tersebut tidak digunakan.

Kalau muatan lebih dari satu grade bukan merupakan alasan untuk tidak melaksanakan Crude Oil Washing pada Tanki-tanki muatan.

Supaya pelaksanaan COW berjalan efektif dimana tekanan balik dari tanki darat dibawah dari tekanan yang diperlukan untuk COW, maka harus diadakan alat Bantu agar supaya tetap pada tekanan minyak yang cukup disupplay ke Mesin Tank Cleaning sesuai pada (a) diatas. Dan ini harus bisa dicapai walaupun salah satu dan pompa-pompa tersebut tidak bisa digunakan.

Tekanan minimum yang diperlukan untuk COW harus dinyatakan dalam Buku "Operation and Equipment Mannual" kalau tekanan minimum mutlak tercapai, maka pelaksanaan operasio COW tidak boleh diteruskan.

\section{Stripping System}

Disain dan kapasitas dari pompa stripper yang digunakan untuk mengeringkan tanki-tanki muatan harus sesuai juga dengan ketentuan-ketentuan dari peraturan-peraturan yang ada.

Stripping system ini tujuan utama penggunaannya untuk mengeringkan dasar tanki dari endapan sisa-sisa minyak dan sediment setelah selesai process COW dalam waktu yang ditentukan $\pm 1,25$ dari watku total pada waktu pelaksanaan COW pada dasar tanki dengan menggunakan semua mesin Tank 
Cleaning yang terpasang seperti yang tercantum dalam buku "Operating and Equipment Mannual”.

Dasar tanki dikatakan sudah kering (dry) kalau jumlah minyak dekat stripping suction sudah sangat sedikit dan tidak ada lagi akumulasi minyak pada tempat-tempat lain dalam tanki.

Sebab itu struktur bagian dalam dari tanki-tanki dibuat sedemikian rupa sehingga pengaliran minyak ke tempat isap dari stripping system berjalan lancer tanpa terganggu.

Pompa yang digunakan untuk stripping adalah jenis "Positive displacement Pump" seperti, Self priming Centripugal Pump atau Eductor.

\section{Pipa balas atau Ballast lines}

Jika kapal tidak dilengkapi dengan pipa balas yang terpisah sama sekali dari pipa-pipa cargo maka harus betul-betul diperhatikan bahwa Cargo Pump manifold dan pipa-pipa yang digunakan untuk balas betul-betul sudah dibersihkan dari sisa-sisa minyak.

\section{Pengoperasian Crude Oil Washing}

\section{Tangki yang akan dibilas dengan crude oil}

Sesudah selesai bongkar muatan dan sebelum berangkat dalam keadaan Balas (Ballast Voyage), sejumlah tanki yang mencukupi sesuai prosedur dalam "Operation and Equipment Mannual" harus sudah dibilas dengan Crude Oil (Crude Oil Wash) dengan ketentuan : Jumlah tanki minimum, yang dapat digunakan sebagai balas untuk memenuhi persyaratan. Marpol Protocol Annex I Reg. 32 a, b, c mengenai :

Sarat kapal ditengah (moulded draft) (dm) dalam meter tidak boleh kurang dari $: \mathrm{Dm}=2.0+0.02 \mathrm{~L}(\mathrm{~L}=96 \% \mathrm{LWL})$ dan Trim kebelakang dari kapal pada Sarat (a) tidak boleh lebih dari 0,015 L. Sarat bagian belakang harus cukup sampai seluruh permukaan baling-baling tenggelam dalam air.

Harus diperhitungkan mengenai daerah pelayaran kapal (ship's traiding patern) terutama keadaan cuaca sehingga kalau diperlukan penambahan air balas jangan sampai dimasukkan dalam tanki yang belum dibilas dengan Crude Oil.

Sebagai tambahan dari ketentuan (a) diatas, kira-kira seperempat dari semua tanki yang tersisa dilaksanakan Crude Oil Wash untuk control dari endapanendapan minyak (Sludge Control) tadi tidak perlu setiap tanki diadakan Crude Oil Wash lebih dari satu kali dalam 4 (empat) bulan.

Crude Oil Washing tidak boleh dilakukan pada waktu pelayaran antara Pelabuhan bongkar terakhir dengan pelabuhan muat atau dengan kata lain tidak diperbolehkan diadakan Crude Oil Wash selama berlayar dalam keadaan balas (ballast Condition).

Air yang dimasukkan dalam tanki yang sudah selesai COW tapi belum dibilas dengan air sebelumnya, harus dianggap sebagai Ballas kotor atau "Dirty Ballast".

\section{Pengisian "Departure Ballast Tank"}

Harus diperhatikan betul-betul setelah selesai Crude Oil Wash pada waktu akan berlayar dengan air ballas tanpa muatan atau "Departure Ballast". 
Pompa-pompa dan pipa-pipa yang digunakan untuk mengisi air balas tersebut harus betul-betul sudah dibersihkan dari sisa-sisa minyak sebelum dilakukan pengisian air balas kedalam tanki balas.

\section{Pelaksanaan Crude Oil Washing dilaut lepas}

Semua pekerjaan COW harus sudah selesai sebelum kapal meninggalkan pelabuhan bongkar muatan terakhir. Kalau sampai dilaksanakan COW antara dua pelabuhan bongkar pada tanki-tanki tersebut harus tetap kosong untuk pemeriksaan pada pelabuhan-pelabuhan berikutnya sebelum diisi dengan air balas.

"Departure Ballast", harus diisi sebelum kapal bertolak dari Pelabuhan bongkar terakhir untuk memungkinkan pemeriksaan permukaan air dalam tankitanki tersebut.

\section{Pembongkaran air-air yang mengandung minyak pada waktu pelayaran dengan air balas}

Pembuangan air balas (Departure ballast) dan campuran-campuran lain air dan minyak dari kapal sewaktu kapal sedang berlayar dengan kondisi balas harus sesuai dengan ketentuan-ketentuan yang disyaratkan dalam Marpol Protocol Reg. 9 dari Annex I sebagai berikut:

1. Untuk kapal Tanker, kecuali yang disebutkan pada butir (b) berikut ini :

a. Tanker tidak berlayar pada daerah-daerah yang sudah ditentukan (special area).

b. Tanker berlayar lebih dari 50 mile laut jauhnya dari Pantai terdekat.

c. Tanker sedang berlayar.Jumlah minyak yang keluar bersama air yang dibuang tidak boleh lebih dari 60 liter setiap 1 (satu) mile laut.Jumlah total minyak yang terbuang kelaut tidak boleh lebih dari : Untuk Tanker bangunan baru (New Tanker) 1/30.000 dari jumlah total muatan yang dimuat.

Kapal Tanker dilengkapi dengan "Oil discharging monitoring and Control System" dan Slop Tank sesuai ketentuan-ketentuan dalam Marpol Protocol.

2. Kapal-kapal selain dari Tanker dengan ukuran 400 GRT keatas dan dari ruangan Kamar Mesin (Bilges) tidak termasuk Bilge dari Cargo Pump :

a. Kapal tidak berlayar pada daerah-daerah yang tertentu (special area).

b. Kapal berlayar lebih dari 12 mile laut dari pantai terdekat.

c. Kapal sedang dalam pelayaran.

d. Jumlah minyak yang keluar bersama air kurang dari 100 parts per million.

e. Kapal dalam operasinya harus dilengkapi dengan Oil discharge monitoring and control system oily water separator Equipment (alat pemisah minyak) atau alat penyaring minyak (Oil filtering system).

Sisa-sisa minyak yang tidak dapat dibuang kelaut karena ketentuanketentuan diatas harus disimpan diatas kapal dan dibongkar ke tempat-tempat penampungan yang disediakan didarat atau pelabuhan.

\section{Keuntungan Menggunakan Crude Oil}

Keuntungan menggunakan Crude Oil antara lain : 
(1) sudah tersedia dikapal dengan cara resirkulasi, (2) efektif untuk menghilangkan sediment dan sisa-sisa minyak yang melekat dalam tangki (good Carrier) dan dibongkar bersama-sama dengan muatan, (3) tidak menimbulkan karat, (4) tidak ada kemungkinan Emulsi air dan minyak jadi mengurangi bahaya polusi.

Disamping keuntungan yang disebutkan diatas sesuai pengalaman dan penyelidikan selama ini akibat sampingan atau kekurangan-kekurangan (Disadvantage) dari Crude Oil Washing ini adalah :

1. Kehilangan muatan (Cargo loss)

Crude Oil Washing dilakukan dengan cara mengsirkulasi sebagian dari Cargo yang sedang dibongkar melalui mesin Tank Cleaning kedalam tanki yang isinya sedang dibongkar dengan disemprotkan dari Nozzle yang berputar kedinding dan alas dari Tanki. Dengan demikian menyebabkan sebagian dari Cargo akan berubah menjadi gas Hydrocarbon yang nantinya setelah tanki tersebut selesai dibongkar/dicuci dengan minyak mentah (COW) dimasukkan Inert Gas untuk mengeluarkan gas Hydrocarbon dari dalam tanki untuk mencegah terjadinya bahaya explosi.

Sesuai pengalaman/penyelidikan oleh British Petrolium Tanker selama ini \pm 0,05\% dari seluruh Cargo hilang menjadi gas, jadi kalau Tanker 100.000 Cargo akan hilang karena COW sekitar 50 ton Crude Oil, yakni didapat dari 0,05\% x 100.000 ton $=50$ ton.

2. Pencemaran lingkungan atau Polusi

Dengan COW akan menimbulkan $\pm 25 \%$ gas Hydrocarbon dalam Tanki lebih tinggi dari pada kalau Cargo dibongkar biasa. Gas ini akhirnya dibuang keudara yang tentunya kadar gas Hydrocarbon cukup tinggi untuk menyebabkan pollusi udara di sekitar tempat membongkar muatan. Untuk mengatasi keadaan ini :

British Petrolium Tanker London sedang mempelajari/menyelidiki bagaimana caranya untuk melequified kembali gas tersebut untuk dapat digunakan lagi dan mungkin dalam waktu dekat mereka akan laksanakan percobaan-percobaan tersebut.

Untuk sementara cara yang ditempuh mengurangi akibat Polusi ini ialah dengan melaksanakan Ballasting dan bongkat muatan bersamaan. Dimana gas Carbon pada Wing Tanks (yang sudah discharge) yang dengan sendirinya dalam keadaan "TOO RICH" dialirkan ke Centre Tanks yang sedang dibongkar menggantikan Inert Gas dari system sementara itu Inert Gas pada System diresirkulasi, dengan demikian mengurangi jumlah gas Hydrocarbon terlepas ke udara.

3. Menambah waktu discharge di Pelabuhan bongkar.

Waktu dapat dikonpensasikan dengan jumlah Cargo lebih banyak dapat dibongkar ke darat (sisa minyak dalam tanki jauh berkurang) apalagi mengingat harga minyak yang semakin meningkat sekarang.

4. Menambah man power dan man hours di pelabuhan jadi anak buah kapal bertambah pekerjaannya. 
Keuntungan lain dari COW selain dari yang kami sebutkan adalah bahwa jumlah Cargo yang dibongkar dari kapal jadi bertambah dibandingkan dengan kalau Tanker tersebut tidak menggunakan peralatan ini.

Sesuai pengalaman BP Tankers selama ini untuk VLCC dengan menggunakan COW maka tambahan jumlah Cargo yang dibongkar bertambah + 1000 ton setiap voyage dibandingkan dengan tanpa menggunakan COW sebelumnya. Jumlah tersebut cukup banyak apalagi mengingat harga minyak yang semakin meningkat.

Jadi dengan menggunakan COW diperkirakan minyak yang akan tumpah kelaut dari kapal dan terminal semakin berkurang.

Menurut penyelidikan kalau untuk kapal-kapal Tanker diatas 150.000 DWT saja melaksanakan seratus proses COW maka diperkirakan 39.000 ton setiap tahun minyak dicegah tumpah kelaut.

Jumlah tersebut sangat berarti untuk pencegahan polusi dan juga untuk penghematan energi.

\section{SIMPULAN}

Penggunaan Crude Oil Washing dapat diperoleh manfaat yang nyata yaitu sudah tersedia di kapal dengan cara resirkulasi, efektif untuk menghilangkan sediment dan sisa-sisa minyak yang melekat dalam tanki (good Carrier) dan dibongkar bersama-sama dengan muatan, tidak menimbulkan karat serta tidak ada kemungkinan emulsi air dan minyak sehingga dapat mengurangi bahaya polusi.

Crude Oil Washing dilakukan dengan cara mengsirkulasi sebagian dari cargo yang sedang dibongkar melalui mesin Tank Cleaning kedalam tanki yang isinya sedang dibongkar dengan disemprotkan dari Nozzle yang berputar kedinding dan alas dari tanki, dengan demikian menyebabkan sebagian dari Cargo akan berubah menjadi gas Hydrocarbon yang nantinya setelah tanki tersebut selesai dibongkar/dicuci dengan minyak mentah (COW) dimasukkan Inert Gas untuk mengeluarkan gas Hydrocarbon dari dalam tanki untuk mencegah terjadinya bahaya explosi.

\section{DAFTAR PUSTAKA}

Badan Diklat Perhubungan Laut, (2000). Crude Oil Washing.

H.M. Dix, (1981). Enviromental Pollution, New York, Brisbane, John Willey \& Sons, Chichester, Toronto.

Pieter Batti,Ir, (1983). Inert Gas System dan Crude Oil Washing,PT Roda Pelita

International Convention For The Safety Of Life at Sea (SOLAS), (1974). Jilid I, Jakarta.

Undang-Undang No.4 Republik Indonesia tentang Lindungan Lingkungan Hidup tahun 1982

Balai Pendidikan Latihan Pelayaran, (1994). Peraturan-peraturan dan Keselamatan Kerja, Semarang 


\section{Tanker Safety Lloyd Registerof Shipping, London}

Balai Pendidikan dan Latihan Pelayaran, (2016). Prosedur Darurat dan SAR, Padang Pariaman. 